\title{
Editorial
}

Journal of Revenue and Pricing Management (2006) 5, 173. doi:10.1057/palgrave.rpm.5160045

One of the primary goals of this journal is to foster academic research and demonstrate how it is used. Over the last five years this journal has seen an enormous growth in the number of researchers actively involved in the subject, the diversity of industry applications, the number of companies providing an in-house function and new terms being invented exclusive to our field. These principles continue with this issue.

In the practice papers section, Kabin offers a method for maintaining corporate profitability and inventory targets in a dynamic business environment by adjusting price and production rates in a manufacturing setting, using scenario analysis. However, Calogridis explores how companies should build a pricing function, starting with the basics through to political consideration. A very insightful paper which explores issues not necessarily found in management science. The research papers section starts off with an interesting paper from Gorin and colleagues at Continental Airlines, who focus on the performance of passenger noshow rates. It describes how the airline has improved forecasting methodologies and processes to show how revenue gains have improved from up to $\$ 90$ million (4 cents per available seat per mile), which represents up to a 10 per cent increase in revenues from overbooking alone. Munnukka explores pricing methods applied when charging mobile service customers, and the influences of the charging methods on the customers' price perceptions. The research for a mobile service provider discovers that pricing methods are a valuable tool for influencing the customers' price perceptions. By providing pricing schemes preferred by customers, a service provider is able to obtain significantly positive results in the form of better price perception levels and higher profitability. Expanding on the theme of telecommunications, Yaripairg and Harmantzis resolve how a pricing network should deal with congestion in an exponentially growth market. The paper presents an auction-based pricing model that is used as an admission control mechanism from mobile data services. Pachon et al. look at how fleet management car rental companies maximise yield by matching capacity to current and projected demand through a three-phased decision-making model.

Looking to the future, Garrow and colleagues from Georgia Institute of Technology review current Revenue Management and Pricing practices in the US across all industries. Some of the trends they note include the recent centralisation of pricing decisions, interest in bundled pricing, and consolidation of demand and supply software providers. Current research directions include finding ways to leverage the unique characteristics of click-stream data and the wealth of customer information to support revenue analysis. Warren Lieberman reviews Bob Philips' new book Pricing and Revenue Optimization. Basically, an excellent contribution to Revenue Management literature. Finally we conclude with a review from the London Revenue Management Club and a list of forthcoming events.

This journal seems to get better with every issue, I would say that. A big thank you to all the contributors and reviewers who helped with this production.

\section{Ian Yeoman} Editor 